\title{
Identification of diagnostic and prognostic biomarkers for cancer: Focusing on genetic variations in microRNA regulatory pathways (Review)
}

\author{
ZHEN GUO ${ }^{1-3}$, YAN SHU ${ }^{4}$, HONGHAO ZHOU $^{1-3}$ and WEI ZHANG ${ }^{1-3}$ \\ ${ }^{1}$ Department of Clinical Pharmacology, Xiangya Hospital, Central South University, Changsha, Hunan 410008; \\ ${ }^{2}$ Institute of Clinical Pharmacology, Hunan Key Laboratory of Pharmacogenetics, Central South University, Changsha, \\ Hunan 410078; ${ }^{3}$ Collaborative Innovation Center for Genetics and Development, School of Life Sciences, Fudan University, \\ Shanghai 200000, P.R. China; ${ }^{4}$ Department of Pharmaceutical Sciences, School of Phamacy, \\ University of Maryland, Baltimore, MD 21201, USA
}

Received January 18, 2015; Accepted December 23, 2015

DOI: $10.3892 / \mathrm{mmr} .2016 .4782$

\begin{abstract}
MicroRNAs (miRNAs) are a highly conserved class of small, noncoding RNAs, which regulate gene expression by post-transcriptional degradation or translational repression. miRNAs are involved in the regulation of cell apoptosis, proliferation, differentiation and other physiological processes. They have been increasingly recognized to be involved in the initiation and progression of human carcinogenesis. More recently, it has been proposed that the genetic variations in miRNA genes, those encoding their biogenesis pathway and target binding sites, may affect the miRNA processing machinery and/or targeting. Polymorphisms in the miRNA regulatory pathway may result in the loss or gain of a miRNA function, which can function as an oncogene or tumor suppressor. Increasing evidence has suggested a marked association between miRNA polymorphisms and cancer diagnosis, treatment efficacy and prognosis. Progress in current understanding of genetic polymorphisms of miRNA regulatory pathways have important implications, not only understanding the pathogenesis of various types of cancer, but also in identifying biomarkers for their diagnosis and prognosis. In the present review, a comprehensive list of potentially functional miRNA-associated single nucleotide polymorphisms are presented, and their importance as candidate cancer biomarkers is discussed.
\end{abstract}

Correspondence to: Professor Wei Zhang, Department of Clinical Pharmacology, Xiangya Hospital, Central South University, 110 Xiang Ya Road, Changsha, Hunan 410008, P.R. China E-mail: yjsd2003@163.com

Key words: microRNA, cancer, genetic variation, susceptibility, prognosis, biomarker

\section{Contents}

1. Introduction

2. Genetic polymorphisms in the miRNA biogenesis pathway

3. Genetic polymorphisms in miRNA genes

4. Genetic polymorphisms in miRNA target sites

5. Scope and challenges

6. Conclusion

\section{Introduction}

MicroRNAs (miRNAs) are small, single-stranded, 21-23 nucleotide-long, independent functional units of noncoding RNA (1-3). Often referred to as the 'micromanagers of gene expression', miRNAs are evolutionarily well-conserved. Mature miRNAs regulate the expression of $\sim 30 \%$ of all human genes involved in fundamental biological processes at a post-transcriptional level by sequence-specific binding to 3'-untranslated regions (3'-UTRs) of multiple target messenger RNAs (mRNAs), leading to their degradation or translational suppression $(4,5)$. Increasing evidence has suggested that miRNAs are important in a broad range of biological processes, including embryonic development, cellular proliferation, differentiation, apoptosis and other physiological processes $(6,7)$.

miRNAs are synthesized in a precisely coordinated manner. Briefly, the miRNA gene is transcribed by RNA polymerase II, resulting in a hairpin-shaped primary miRNA (pri-miRNA), which is $\sim 500-3,000$ base pairs in length. This pri-miRNA is further processed by Drosha/Pasha (DGCR8) to form a 60-70 nucleotide-long precursor miRNA (pre-miRNA), which is transported from the nucleus to the cytoplasm through nuclear pore complexes, with the assistance of Exportin-5 (XPO5) $(6,8)$. The pre-miRNA is further cleaved in the cytoplasm by the RNase III endonuclease, Dicer, to release two complementary short RNA molecules (9). The argonaut protein complex selectively binds to the guide strand and facilitates the formation of a miRNA-mRNA-induced silencing complex (RISC) assembly, which consists of HIWI, GEMIN3 and GEMIN4. Upon miRNA 
binding, the RISC complex is activated and, by a mechanism that remains to be fully elucidated, locates its binding site in the 3'-UTR of the target mRNA and contributes to regulation of the expression of the gene (8-10).

Advancements in investigations of miRNA have indicated the involvement of miRNAs in the genesis, progression (proliferation, migration and invasion) and prognosis of multiple types of human malignancy (11). Of note, $~ 50 \%$ of all annotated human miRNA genes are located in fragile sites or areas of the genome, which are frequently deleted, amplified and mis-expressed in human cancer (12). The conditional deletion or overexpression of a single miRNA is sufficient to drive tumorigenesis in mice (13). It has been suggested that the single nucleotide polymorphisms (SNPs) in miRNAs, which encode their biogenesis pathway and target binding sites, may affect the regulatory capacity of miRNAs by affecting miRNA processing and/or miRNA-mRNA interactions (14). Polymorphisms in miRNA regulatory pathways may result in the loss or gain of an miRNA function, which can act as an oncogene or tumor suppressor. Previously, several studies have demonstrated a marked association between miRNA-polymorphisms and the risk, treatment response and outcome in patients with cancer $(15,16)$. Polymorphisms in miRNA regulatory networks are a novel class of functional polymorphisms in the human genome (11). These enable investigation of the biology of cancer and have the potential for use as biomarkers in cancer diagnosis and prognosis. The present review provides a brief outlook on the biogenesis and biology of miRNAs, and the functional effects of miRNA-associated SNPs.

\section{Genetic polymorphisms in the miRNA biogenesis pathway}

Several proteins and protein complexes are involved in various stages of miRNA biogenesis, including miRNA transcription, processing, export and targeting (7). These proteins include the RNA polymerase II complex, Drosha/Pasha, Exportin-5, nuclear pore complexes, Dicer and the Argonaut protein/RISC complex, as shown in Fig. 1. As the underexpression or overexpression of miRNA may have serious consequences in a cell, polymorphisms in core components of miRNA biogenesis may impair or enhance miRNA processing efficiency or function, resulting in altered levels of mature miRNAs and deleterious effects (4). Several lines of evidence have supported that SNPs in the biogenesis pathway of miRNAs are associated with development and progression in a several types of tumor (Table I).

DROSHA. Drosha is an RNAse III enzyme, which mediates the processing of pri-miRNAs into pre-miRNAs with DGCR8 (8). In a previous in vitro functional investigation, a reduction in miRNA processing efficacy, which was induced by the knockdown of DROSHA, was found to reduce the levels of mature forms of tumor-suppressive miRNAs and facilitate the invasion of breast cancer cells (17). Several studies have indicated the role of Drosha in breast cancer. A case-control study demonstrated that two SNPs in DROSHA, rs644236 and $r s 7737174$, may contribute to the risk of breast cancer in postmenopausal women (18). Jiang et al also suggested $r s 2291109$ as a predictor for breast cancer risk, however, the association was not confirmed (19). In addition, patients with breast cancer carrying the DROSHA rs $874332 \mathrm{C}$ allele are at increased risk of mortality (20). As rs 874332 is located in the 3'-UTR of DROSHA mRNA and a predicted miRNA binding site, it is possible that $r s 874332$ may be correlated with the translational repression and mRNA destabilization of DROSHA through an miRNA-mRNA interaction. However, data from Sung et al (21) involving east Asian women, including 5,066 cases and 4,337 controls, failed to identify an association between the SNPs in DROSHA and breast cancer risk. In addition, DROSHA rs 6877842 has been reported to reduce the risk of recurrence in patients with renal cell carcinoma by $36 \%$, and haplotypes of DROSHA (rs6877842/rs10719) have been associated with survival rates (22). rs10719 may also affect the risk of malignant peripheral nerve sheath tumors through increasing the expression level of DROSHA (23).

DGCR8 (Pasha). DGCR8, as a component of the multiprotein complex with the RNAse III enzyme, Drosha, is a double stranded RNA-binding protein, which is involved in the processing of pri-miRNAs into pre-miRNAs (9). Impaired miRNA processing through the knockdown of DGCR8 also facilitates the invasion of breast cancer cells (17). The rs9605062 in DGCR8 may upregulate the level or timing of gene expression (20), and it has been reported that $r s 9606250$ is significantly associated with poor disease-free survival (DFS) rates in breast cancer (20). In addition, the interruption of miRNA binding of $r s 417309$, located at the binding sites of miR-106b and miR-579 in the 3'-UTR of DGCR8, has been found to increased the risk of breast in the Chinese population (19). Another two linked SNPs, rs2073778 and rs720012, in DGCR8 have also been shown to be significantly associated with tumor progression in bladder cancer (24).

XPO5.XPO5 is located in the nuclear membrane, and mediates the transport of pre-miRNAs to regulate miRNA expression (10). The XPO5-mediated nuclear export of pre-miRNAs may be a rate-limiting step in miRNA biogenesis. The overexpression of XPO5 has been shown to result in enhanced miRNA activity (25), whereas the loss of XPO5 leads to reduced expression and function of pre-miRNAs (26). Among the SNPs in XPO5, rs 11077 has received the most attention. Located in the 3'-UTR of XPO5, rs 11077 may affect mRNA stability, alter the expression of XPO5 and, consequently, affect the expression of miRNAs, including those specific for drug metabolism, altering the response to chemotherapy and affecting survival rates of patients with advanced non-smallcell lung cancer (NSCLC) and small-cell lung cancer $(27,28)$. In addition, $r s 11077$ has been associated with poor progression in hepatocellular carcinoma and renal cell carcinoma $(22,29)$. A mutation in $r$ s 11544382 in a functionally conserved region of XPO5 may also alter the protein structure of XPO5, resulting in altered nucleocytoplasmic transport activity (30), and this SNP has been associated with an increased risk of breast cancer (30).

DICER. Dicer is an enzyme responsible for the cleavage of miRNA precursors, and has been implicated in the oncogenic process of several types of cancer. Increasing evidence has supported the role of DICER rs 1057035 in cancer susceptibility. This SNP has been associated with a decreased risk of oral cancer (31), cervical carcinoma (32) and hepatocellular 
Table I. Polymorphisms in microRNA biogenesis pathways and functional variations.

\begin{tabular}{|c|c|c|c|c|c|}
\hline Biogenesis gene & SNP site & Tumor type (population, n) & Description & Risk $(95 \% \mathrm{CI})$ & Ref \\
\hline \multirow[t]{6}{*}{ DROSHA } & rs874332 (C>T) & Breast cancer (Korean, 488) & $\mathrm{OS}$ & $\mathrm{HR}=2.24(1.21-4.17)$ & 20 \\
\hline & rs644236 $(\mathrm{C}>\mathrm{T})$ & Breast cancer (Korean, 559/567) & Susceptibility & $\mathrm{OR}=1.27(0.94-1.73)$ & 18 \\
\hline & rs7737174 (A>G) & Breast cancer (Korean, 559/567) & Susceptibility & $\mathrm{OR}=1.63(1.01-2.64)$ & 18 \\
\hline & rs2291109 $(\mathrm{A}>\mathrm{T})$ & $\begin{array}{l}\text { Breast cancer (Chinese, } \\
878 / 900)\end{array}$ & Susceptibility & $\mathrm{OR}=0.81(0.66-0.99)$ & 19 \\
\hline & $\operatorname{rs} 6877842(\mathrm{C}>\mathrm{G})$ & $\begin{array}{l}\text { Renal cell carcinoma } \\
\text { (Caucasian, } 316)\end{array}$ & Recurrence & $\mathrm{HR}=0.36(0.13-0.98)$ & 22 \\
\hline & rs $10719(\mathrm{C}>\mathrm{T})$ & $\begin{array}{l}\text { Malignant peripheral nerve sheath } \\
\text { tumor (Chinese, 156/200) }\end{array}$ & Susceptibility & $\mathrm{OR}=1.64(1.23-2.20)$ & 23 \\
\hline \multirow[t]{3}{*}{ DGCR8 } & rs9606250 (A>T) & Breast cancer (Korean, 488) & DFS & $\mathrm{HR}=0.21(0.05-0.84)$ & 20 \\
\hline & rs417309 $(\mathrm{A}>\mathrm{G})$ & $\begin{array}{l}\text { Breast cancer (Chinese, 878/ } \\
900 \text { ) }\end{array}$ & Susceptibility & $\mathrm{OR}=1.50(1.16-1.93)$ & 19 \\
\hline & rs2073778 (C>T) & $\begin{array}{l}\text { Bladder cancer (non- } \\
\text { Hispanic, 421) }\end{array}$ & Progression & $\mathrm{HR}=4.00(1.53-10.46)$ & 24 \\
\hline \multirow[t]{5}{*}{ XPO5 } & rs11077 (A>C) & NSCLC (Chinese, 112) & $\mathrm{OS}$ & $\mathrm{RR}=0.457(0.251-0.831)$ & 27 \\
\hline & & SCLC (Chinese, 42) & OS & $\mathrm{RR}=2.469(1.088-5.603)$ & 28 \\
\hline & & $\begin{array}{l}\text { Hepatocellular carcinoma } \\
\text { (Chinese, 108) }\end{array}$ & OS & $\mathrm{RR}=0.395(0.167-0.933)$ & 29 \\
\hline & & $\begin{array}{l}\text { Renal cell carcinoma } \\
\text { (Caucasian, 316) }\end{array}$ & Recurrence & $\mathrm{HR}=0.36(0.16-0.85)$ & 22 \\
\hline & rs $11544382(\mathrm{~A}>\mathrm{G})$ & $\begin{array}{l}\text { Breast cancer (Caucasian, } \\
441 / 479)\end{array}$ & Susceptibility & $\mathrm{OR}=1.59(1.06-2.39)$ & 30 \\
\hline \multirow[t]{5}{*}{ DICER } & rs $1057035(\mathrm{C}>\mathrm{T})$ & $\begin{array}{l}\text { Head and neck cancer } \\
\text { (Chinese, 397/900) }\end{array}$ & Susceptibility & $\mathrm{OR}=0.65(0.46-0.92)$ & 31 \\
\hline & & $\begin{array}{l}\text { Cervical carcinoma } \\
(\text { Chinese, } 1,486 / 1,549)\end{array}$ & Susceptibility & $\mathrm{OR}=0.962(0.805-1.149)$ & 32 \\
\hline & & $\begin{array}{l}\text { Hepatocellular carcinoma } \\
\text { (Chinese, 1300/1344) }\end{array}$ & Susceptibility & $\mathrm{OR}=0.79(0.64-0.96)$ & 33 \\
\hline & & Breast cancer (Korean, 488) & DFS & $\mathrm{HR}=1.72(0.99-2.99)$ & 20 \\
\hline & & & OS & $\mathrm{HR}=2.08(1.01-4.28)$ & \\
\hline \multirow[t]{6}{*}{ GEMIN4 } & rs7813 $(\mathrm{C}>\mathrm{T})$ & $\begin{array}{l}\text { Renal cell carcinoma } \\
\text { (Caucasian, 316) }\end{array}$ & OS & $\mathrm{HR}=1.74(1.15-2.62)$ & 22 \\
\hline & & $\begin{array}{l}\text { Prostate cancer } \\
\text { (Chinese, 300/244) }\end{array}$ & Susceptibility & $\mathrm{OR}=2.53(1.07-6.28)$ & 34 \\
\hline & & $\begin{array}{l}\text { Malignant peripheral nerve } \\
\text { sheath tumor (Chinese, } \\
156 / 200 \text { ) }\end{array}$ & Susceptibility & $\mathrm{OR}=0.50(0.34-0.72)$ & 23 \\
\hline & & $\begin{array}{l}\text { Ovarian cancer } \\
\text { (Caucasian, 339/349) }\end{array}$ & Susceptibility & $\mathrm{OR}=0.71(0.57-0.87)$ & 35 \\
\hline & rs2740348 (C>G) & $\begin{array}{l}\text { Renal cell carcinoma } \\
\text { (Caucasian, 279/278) }\end{array}$ & Susceptibility & $\mathrm{OR}=0.67(0.47-0.96)$ & 36 \\
\hline & & $\begin{array}{l}\text { Prostate cancer } \\
\text { (Chinese, 300/244) }\end{array}$ & Susceptibility & $\mathrm{OR}=0.68(0.47-0.98)$ & 34 \\
\hline \multirow[t]{5}{*}{$\mathrm{AGO} 2$} & rs2292779 (C>G) & Breast cancer (Korean, 488) & DFS & $\mathrm{HR}=1.42(1.06-1.92)$ & 20 \\
\hline & & & OS & $\mathrm{HR}=2.94(1.52-5.69)$ & \\
\hline & rs $11786030(A>G)$ & Breast cancer (Korean, 488) & DFS & $\mathrm{HR}=2.62(1.41-4.88)$ & 20 \\
\hline & & & OS & $\mathrm{HR}=2.41(1.05-5.50)$ & \\
\hline & $\operatorname{rs} 3864659(\mathrm{~A}>\mathrm{C})$ & Breast cancer (Korean, 559/567) & Susceptibility & $\mathrm{OR}=0.67(0.46-0.96)$ & 18 \\
\hline
\end{tabular}

NSCLC, non-small-cell lung cancer; SCLC, small-cell lung cancer; OS, overall survival; DFS, disease-free survival; HR, hazard ratio; OR, odds ratio; $\mathrm{RR}$, relative risk. 


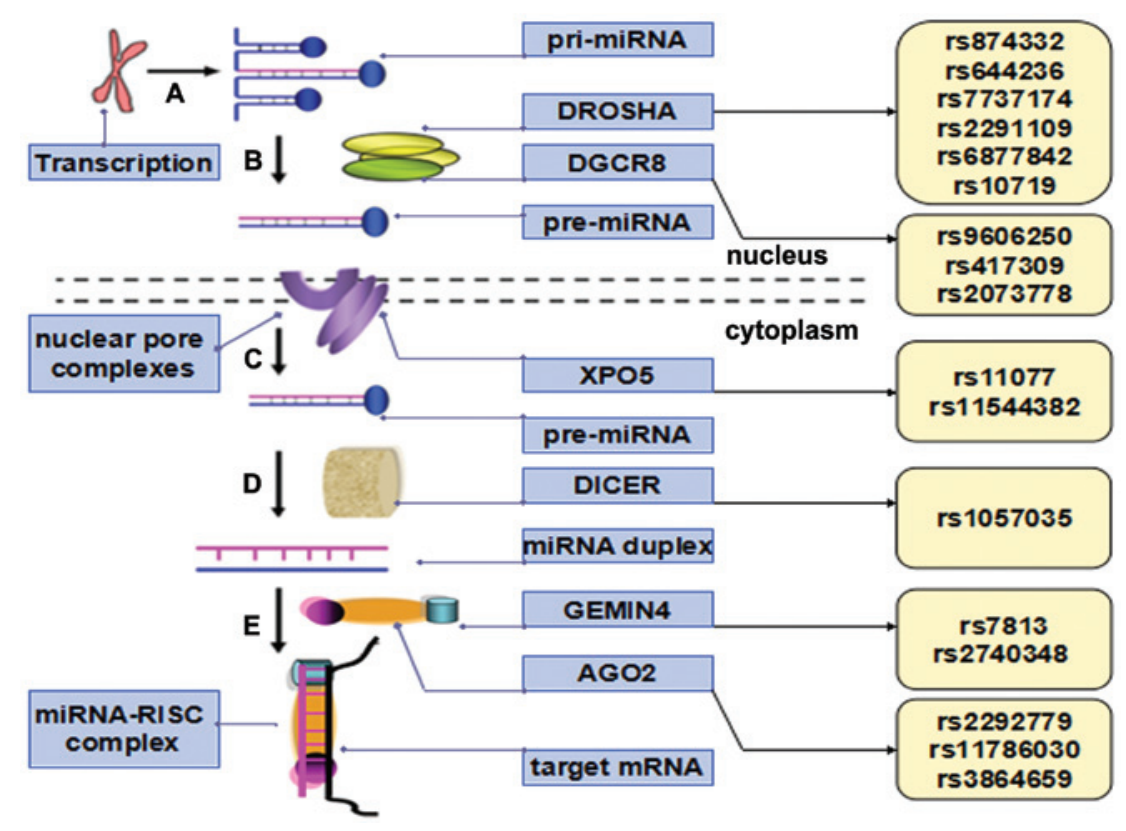

Figure 1. Illustrative overview of polymorphisms in miRNA biogenesis pathways. (A) miRNA gene is transcribed by RNA polymerase II; (B) pri-miRNA is further processed by Drosha/Pasha; (C) pre-miRNA is transported to the cytoplasm by Exportin-5; (D) pre-miRNA is cleaved by Dicer, releasing two complementary short RNA molecules; (E) miRNA-RISC complex binds to the 3'-untranslated reguin of the target mRNA and contributes to translational inhibition or mRNA degradation. Polymorphisms, which affect the expression of proteins involved in miRNA action and biogenesis, including Drosha, Pasha, Dicer, Exportin 5 and proteins in the RISC complex, may affect miRNA-mediated regulation of mRNA expression and protein translation in the cell, consequently, contributing to the susceptibility and prognosis of various types of cancer. miRNA, microRNA; pri-miRNA, primary miRNA; pre-miRNA, precursor miRNA; RISC. RNA-induced silencing complex.

carcinoma (33). This polymorphism is located in the 3'-UTR of DICER and a predicted binding site of miR-574-3p, which may affect the binding of miR-574-3p, and result in decreased mRNA expression levels of DICER (31). Of note, this SNP has been shown to be associated with a 1.72- and 2.08-fold increased risk of progression and cancer-associated mortality, respectively, among patients with breast cancer (20).

GEMIN4. The GEMIN4 protein is referred to as an important molecule in the RISC complex, which is involved in the maturation process of miRNAs, and the recognition and repression of target mRNAs (7). The protein expression level of GEMIN4 is closely associated with the biogenesis of associated miRNAs (7). Rs7813 in the exons of GEMIN4 has been frequently identified as a predictive biomarker in several types of cancer, including renal cell carcinoma (22), prostate cancer (34), malignant peripheral nerve sheath tumor (23) and ovarian cancer (35). Another non-synonymous SNP, rs2740348, which is located in the functional region of the GEMIN4 gene has been demonstrated to decrease the risks of prostate cancer and renal cell carcinoma by 36 and $33 \%$, respectively $(34,36)$. Notably, Wan et al found that $r s 2740348$ and $r s 7813$ were significantly associated with cell growth and DNA repair in a heptacellular carcinoma cell line (37), suggesting that the amino acid changes caused by these SNPs may have a physiological significance on the development of cancer.

AGO2. AGO2 is important in miRNA-mediated gene silencing, as a component of the RISC complex that directly binds miRNAs and mediates the cleavage of target mRNAs (7). Emerging evidence from in vitro analysis and clinical samples has indicated that the abnormal expression or enzymatic function of
AGO2 is associated with cancer development and progression. In breast cancer cell lines, the overexpression of AGO2 induces the transformed phenotype (38). Sung et al indicated that AGO2 rs3864659 may have a protective effect on breast cancer risk (18). In addition, two further SNPs in AGO2 rs 11786030 and $r s 2292779$ have been significantly associated with poor DFS and poor overall survival (OS) rates in breast cancer (20). Variations in the genomic structure of $A G O 2$, including changes in copy number or frameshift mutations, have also been reported to be associated with several types of cancer, including multiple myeloma, gastric cancer and colorectal cancer $(39,40)$.

\section{Genetic polymorphisms in miRNA genes}

SNPs in miRNA genes are considered to exert their effects by one of three mechanisms: Through transcription of the primary transcript; through pri-miRNA and pre-miRNA processing; and through effects on miRNA-mRNA interactions (11). In general, sequence variations in miRNA genes, including pri-miRNAs, pre-miRNAs and mature miRNAs, have the potential of affect the processing efficiency and/or target selection of miRNAs, leading to aberrant expression of hundreds of genes in different biological pathways (11). As miRNAs are highly conserved, SNPs in miRNA genes are relatively rare. The majority of studies have followed a biologically-based candidate gene approach to identify SNPs in miRNAs, which may affect cancer susceptibility, relying on a knowledge of the functional link between a particular miRNA and gene target (Table II).

Pre-miR-27a. The pre-miR-27a, rs895819, has been frequently investigated in the development of cancer, however, the results remain contradictory rather than conclusive (41-46). To inte- 
grate all individual studies and comprehensively analyze the role of rs 895819 in tumorigenesis, several meta-analysis have been performed. Previous overall meta-analysis suggested no association between the pre-miR-27a $r s 895819$ polymorphism and cancer susceptibility (47-49). In a stratified analysis, according to the type of cancer, individuals with the variant $\mathrm{G}$ allele were consistently found to be at a reduced risk of breast, renal cell and nasopharyngeal cancer, but at an increased risk of digestive tract cancer (47). In addition, subgroup analysis according to ethnicity revealed that the $r$ 895819 AG genotype was associated with a decreased risk of cancer in Caucasian individuals (48). As this SNP is located at the terminal loop of pre-miR-27a, it may have an effect on the secondary structure of pre-miR-27a (42). The substitution of G for A in rs 895819 may reduce the size of the loop and alter the minimum free energy, consequently inhibiting cleavage and resulting in low expression levels of mature miR-27a (42).

miR-196a2. rs11614913 in the mature sequence of miR-196a2 has been increasingly identified a predictor for various types of cancer (50-52). The results from several meta-analyses, each containing thousands of subjects, have demonstrated that rs11614913 may contribute to the risk of developing breast cancer (53), lung cancer $(54,55)$, hepatocellular carcinoma (56) and cancer of the digestive system $(57,58)$. In addition, the SNP was positively correlated with improved recurrence-free survival (RFS) in patients with stage II and stage III NSCLC (59). The polymorphism may negatively affect endogenous processing of either miR-196a2 precursor to its mature form, and the levels of mature miR-196a2 are lower in CC carriers, compared with TT carriers (60). Furthermore, binding assays have revealed that this SNP can affect the binding of mature miR-196a 2 to its target mRNA (60).

miR-146a. miR-146a, first identified in the mouse, has been shown to be important in tumorigenesis, by promoting cell proliferation and colony formation in NIH/3T3 cells (61). However, it also exhibits an antitumor property, by suppressing metastatic ability, in breast cancer and prostate cancer $(62,63)$. The G-C substitution ( $r s 2910164)$, located in the middle of the stem hairpin on the passenger strand of the precursor miR-146a, has a lower transcriptional activity due to decreased nuclear processing efficiency, leading to low level of mature miR-146a in cells (64). Although three meta-analyses consistently found that rs2910164 was not involved in overall cancer risk, stratified analysis by ethnicity has shown a close association between rs2910164 and overall cancer risk in the Caucasian population (50-52). Jiang et al reported that the $r s 2910164 \mathrm{GG}$ homozygote was a protective genotype, in terms of susceptibility to acute-on-chronic hepatitis B liver failure (65). However, results from another meta-analysis showed the $\mathrm{C}$ variant to be associated with decreased hepatocellular carcinoma risk (56). As for patients with NSCLC, variants of $r s 2910164$ were found to be positively correlated with RFS (59). However, in the development of cervical squamous cell carcinoma, the $\mathrm{G}$ allele of $r s 2910164$ was associated with a significantly increased risk, as well as reduced tumor differentiation and a decline in lymph node status (66). $m i R-499$. It is known that the secondary structure of miRNA is critical to mRNA-miRNA interactions and gene regulation (67). The rs3746444 polymorphism may affect miR-499 maturation and regulate the expression of its target genes through directly altering its secondary structure. Zhou et al provided evidence that $r s 3746444$ may contribute to the susceptibility to cervical squamous cell carcinoma (66). Of note, Liu et al demonstrated that $r s 3746444$ has a protective effect in the development of head and neck cancer (68). In addition, the T allele of $r s 3746444$ was associated with a decreased risk of breast cancer among Asian individuals, however, a follow-up meta-analysis suggested risk was increased in Caucasians individuals, suggesting ethnic differences in the consequences of SNPs (69). A further meta-analysis failed to identify any significant correlation between the miR-499 polymorphism and risk of hepatocellular carcinoma (56).

$m i R-218$. The expression level of miR-218 is associated with infection with high-risk human papilloma virus (HPV), and is involved in the pathogenesis of cervical cancer (70). The rs 11134527 in miR-218 has been shown to upregulate the expression of miR-218, and inhibit the expression of its target gene, $L A M B 3$, by interfering with the mRNA-miRNA interaction. The overexpression of $L A M B 3$ induces carcinogenesis by increasing carcinoma cell migration and disturbing tumor microenvironment, therefore, this polymorphism has been implicated in the infective process of high-risk HPV, thus contributing to cervical carcinogenesis $(66,71)$. Another study evaluated the role of $r$ s 11134527 in hepatocellular carcinoma, which noted that the AG genotype of $r$ s11134527 was associated with family history and elevated levels of serum $\alpha$-fetoprotein, suggesting that the AG genotype may be associated with genetic predisposition in patients with hepatocellular carcinoma (72).

\section{Genetic polymorphisms in miRNA target sites}

The disruption of miRNA-dependent regulation by SNPs in the miRNA binding site of target mRNAs has been confirmed as a mechanism for altered gene expression in cancer. In contrast to the miRNA-polymorphisms in the miRNA biogenesis pathway, the polymorphisms located at the 3'-UTR of an miRNA target gene are more abundant in the human genome, and affect only the expression of the target gene and its downstream effectors, resulting in a more defined and limited range of effects (73). The majority of the miRNA binding sites in the 3'-UTRs of a target mRNA lack a complex secondary structure, thereby facilitating access for an miRNA. Polymorphisms at or close to these binding sites, through creating or eradicating secondary structure, may affect the accessibility of an miRNA-RISC complex, and the coordination of miRNAs with other regulatory elements in the 3'-UTR of the target transcript (11). Among the 120,000 known SNPs that occur in 3'-UTRs, $17 \%$ destroy putative conserved or non-conserved miRNA-binding sites, and $8.6 \%$ create novel predicted target sites, according to the Patrocles database (74). Several examples of SNPs located in the 3'-UTR of target mRNAs, and their clinical significance, are presented in Table III.

FAS is a cell surface receptor of the tumor necrosis family, which is important in the regulation of apoptosis (75). The $r s 2234978$ SNP in the 3'-UTR of FAS has been reported to 
Table II. Polymorphisms in miRNA genes and their clinical significance.

\begin{tabular}{|c|c|c|c|c|c|}
\hline miRNA & SNP site & Tumor type (population, n) & Description & Risk (95\% CI) & Ref \\
\hline \multirow[t]{4}{*}{ pre-miR-27a } & $\operatorname{rs} 895819(A>G)$ & Breast cancer (Chinese, 264/255) & Susceptibility & $\mathrm{OR}=0.535(0.321-0.891)$ & 42 \\
\hline & & $\begin{array}{l}\text { Renal cell carcinoma } \\
\text { (Chinese, } 594 / 600)\end{array}$ & Susceptibility & $\mathrm{OR}=0.71(0.56-0.90)$ & 44 \\
\hline & & NSCLC (Chinese, 576) & OS & $\mathrm{HR}=1.71(1.12-2.26)$ & 45 \\
\hline & & & $\begin{array}{l}\text { Chemotherapy } \\
\text { response }\end{array}$ & $\mathrm{OR}=0.54(0.32-0.91)$ & \\
\hline \multirow[t]{5}{*}{ miR-196a2 } & $\operatorname{rs} 11614913(\mathrm{C}>\mathrm{T})$ & Breast cancer (meta, 2588/3260) & Susceptibility & $\mathrm{OR}=0.906(0.825-0.995)$ & 53 \\
\hline & & Lung cancer (meta, 2219/2232) & Susceptibility & $\mathrm{OR}=1.13(0.98-1.29)$ & 55 \\
\hline & & $\begin{array}{l}\text { Hepatocellular carcinoma } \\
\text { (meta, 3437/3437) }\end{array}$ & Susceptibility & $\mathrm{OR}=0.90(0.83-0.98)$ & 56 \\
\hline & & $\begin{array}{l}\text { Digestive system cancers } \\
\text { (meta, 4999/7606) }\end{array}$ & Susceptibility & $\mathrm{OR}=1.29(1.10-1.50)$ & 58 \\
\hline & & NSCLC (Korean, 388) & RFS & $\mathrm{HR}=0.60(0.38-0.94)$ & 59 \\
\hline \multirow[t]{3}{*}{ miR-146a } & rs2910164 (C>G) & $\begin{array}{l}\text { Acute-on-chronic hepatitis B liver } \\
\text { failure (Chinese, } 717 / 251 \text { ) }\end{array}$ & Susceptibility & $\mathrm{OR}=0.496(0.309-0.797)$ & 65 \\
\hline & & NSCLC (Korean, 388) & RFS & $\mathrm{HR}=0.48(0.28-0.80)$ & 59 \\
\hline & & $\begin{array}{l}\text { Cervical squamous cell carcinoma } \\
\text { (Chinese, 226/309) }\end{array}$ & Susceptibility & $\mathrm{OR}=2.10(1.22-3.59)$ & 66 \\
\hline \multirow[t]{2}{*}{ miR-499 } & rs3746444 (C>T) & $\begin{array}{l}\text { Cervical squamous cellcarcinoma } \\
\text { (Chinese, 226/309) }\end{array}$ & Susceptibility & $\mathrm{OR}=1.78(1.24-2.56)$ & 66 \\
\hline & & $\begin{array}{l}\text { Head and neck cancer (non-Hispanic } \\
\text { white, 1109/1130) }\end{array}$ & Susceptibility & $\mathrm{OR}=0.83(0.69-0.99)$ & 68 \\
\hline \multirow[t]{2}{*}{ pri-miR-218 } & rs11134527 (A>G) & $\begin{array}{l}\text { Cervical carcinoma } \\
\text { (Chinese, 1584/1394) }\end{array}$ & Susceptibility & $\mathrm{OR}=0.77(0.63-0.95)$ & 71 \\
\hline & & $\begin{array}{l}\text { Hepatocellular carcinoma } \\
\text { (Chinese, 302/513) }\end{array}$ & Susceptibility & $\mathrm{OR}=2.96(1.16-7.56)$ & 72 \\
\hline
\end{tabular}

miRNA, microRNA; SNP, single nucleotide polymorphism; NSCLC, non-small-cell lung cancer; meta, meta-analysis; OS, overall survival; HR, hazard ratio; OR, odds ratio; RFS, recurrence-free survival; Ref, reference.

Table III. Polymorphisms in miRNA target sites and the effects of the variability.

\begin{tabular}{|c|c|c|c|c|c|c|}
\hline Target gene & SNP site & miRNA & Tumor type (population, n) & Description & Risk (95\% CI) & Ref \\
\hline FAS & rs2234978 (C>T) & miR-561 & NSCLC (Caucasian, 535) & OS & $\mathrm{HR}=0.59(0.44-0.77)$ & 74 \\
\hline FZD4 & rs713065 $(A>G)$ & miR-494 & NSCLC (Caucasian, 535) & OS & $\mathrm{HR}=0.46(0.32-0.65)$ & 74 \\
\hline SP1 & rs $17695156(\mathrm{C}>\mathrm{T})$ & miR-545 & NSCLC (Caucasian, 535) & Recurrence & $\mathrm{HR}=3.36(1.62-6.69)$ & 74 \\
\hline \multirow[t]{3}{*}{ MDM4 } & rs4245739 $(\mathrm{A}>\mathrm{C})$ & miR-191 & $\begin{array}{l}\text { Esophageal squamous cell } \\
\text { carcinoma (Chinese, } \\
1128 / 1150)\end{array}$ & Susceptibility & $\mathrm{OR}=0.54(0.35-0.82)$ & 76 \\
\hline & & miR-191 & $\begin{array}{l}\text { Ovarian carcinoma } \\
\text { (Caucasian, 113) }\end{array}$ & Mortality & $\mathrm{HR}=5.5(1.5-20.5)$ & 77 \\
\hline & & & & Recurrence & $\mathrm{HR}=4.1(1.2-13.5)$ & \\
\hline SGSM3 & $\begin{array}{l}\text { rs56228771 } \\
\text { (insertion/deletion) }\end{array}$ & miR-151-5p & $\begin{array}{l}\text { Hepatocellular carcinoma } \\
(\text { Chinese, } 502 / 513)\end{array}$ & Susceptibility & $\mathrm{OR}=0.55(0.42-0.73)$ & 78 \\
\hline COL1A2 & $\begin{array}{l}\text { rs3917 } \\
\text { (insertion/deletion) }\end{array}$ & miR-382 let-7g & $\begin{array}{l}\text { Hepatocellular carcinoma } \\
(\text { Chinese, } 207 / 245)\end{array}$ & Susceptibility & $\mathrm{OR}=1.76(1.03-3.01)$ & 79 \\
\hline
\end{tabular}

miRNA, microRNA; SNP, single nucleotide polymorphism; NSCLC, non-small-cell lung cancer;OS, overall survival; HR, hazard ratio; OR, odds ratio; Ref, reference. 
create a novel miRNA-binding site for miR-561, and ultimately result in decreased expression of FAS. Patients with NSCLC, who carry the variant allele, appear to have a better overall survival (OS), independent of treatment regimen (75). This may be explained by higher expression levels of FAS due to the SNP, which may increase tumor cell death. Similarly, rs 713065 in the 3'-UTR of FZD4 may downregulate the expression of FZD4 by creating an miR-494 binding site, leading to enhanced survival through decreased WNT signaling (76). By contrast, rs 17695156 in the 3'-UTR of SPl is predicted to disrupt a conserved miR-545 binding site and alter the expression of SP1 by affecting mRNA stability or post-transcriptional regulation, and patients with NSCLC patients carrying at least one variant allele of $r s 17695156$ have a shorter median RFS, compared with patients with a common homozygous genotype (75). The $r s 4245739$ SNP in the 3'-UTR of MDM4 has been noted to create an miR-191 target site and results in decreased expression of MDM4 (76). As MDM4 is key in the P53 tumor suppressor pathway, by negatively regulating P53 function, this polymorphism may contribute to reduced susceptibility to esophageal squamous cell carcinoma (77). In addition, AA genotype carriers, who do not express the estrogen receptor, have a 4.2-fold increased risk of recurrence and a 5.5-fold increased risk of tumor-associated mortality in ovarian cancer (78).

In addition to SNPs, the insertion/deletion polymorphisms in a target gene can also create or destroy a binding site. SGSM3 is involved in the small G protein-coupled receptor signal transduction pathway. It has been reported that a 4-bp insertion/deletion polymorphism (rs56228771) in the 3'-UTR of SGSM3 can affect the susceptibility of hepatocellular carcinoma, reducing decreased risk of ins/del+ins/ins genotypes by 45\% (79). In addition, a 7-base pair deletion polymorphism (rs3917) in the 3'-UTR of COL1A2 has been associated with a 1.73-fold increased risk of hepatocellular carcinoma (80). The $r s 3917$ lies within a predicted binding site for miR-382 and let- $7 \mathrm{~g}$, and the deletion allele may alter the affinity of miRNA-mRNA binding, by disrupting the local structure of COL1A2 mRNA, possibly upregulating the expression of COL1A2 $(80,81)$.

\section{Scope and challenges}

Further investigations. To date, the majority of the studies in this field are case-control studies, based on a candidate gene approach (15). Although several positive results have been reported, inconsistent findings and non-replication of previous results have frequently occurred (15). This may be attributed to several reasons, including the heterogeneity of patient groups, different experimental designs, insufficient sample size or unclear disease biology (15).

Heterogeneity in clinical confounding factors and endpoint phenotypes between initial and replication studies can undermine the opportunity to compare among them. It is essential to account for all confounding factors, which may predispose to a given phenotype, in order to estimate the residual phenotype that is likely due to genetics. As a small sample size can provide imprecise or incorrect estimates of the magnitude of an observed effect, sufficient sample size is necessary to accurately distinguish a suggested effect from a lack of effect (82). As several initial studies have been reported in populations of European descent, the challenge remains to extend investigations to include other ethnic populations (82).

Well-planned investigations are required, providing sufficient statistical power and stringency to detect and quantify a modest impact of the investigated SNPs. Follow-up epidemiological association investigations are important to validate previous findings in multiple independent large and homogenous samples. The National Cancer Institute-National Human Genome Research Institute working group on replication in association studies has published a comprehensive set of guidelines, providing a number of essential criteria for establishing positive replication studies (83).

Investigation of biological mechanisms. In addition, further functional investigations are required to clarify the underlying mechanism. Several miRNAs are found in $\mathrm{CpG}$ islands, and miRNA expression can also be affected by DNA methylation and histone deacetylase inhibitors, providing another example of the bivalent roles of how miRNAs in malignancy (84). For example, two well-defined tumor suppressors, miR-124 and miR-34, are subject to epigenetic silencing by aberrant DNA hypermethylation, affecting cell cycle pathways in tumors, whereas the downregulation of miR-34 affects the Notch pathway, which is involved in cell invasion and apoptosis (85-87). Furthermore, DNA methylation profiles in miRNA promoter regions can be useful as a diagnostic and prognostic marker. For example, miR-23b, an miRNA with tumor suppressor activity in prostate cancer, is downregulated through DNA hypermethylation of its promoter region, and its expression level is correlated with OS and RFS (88). In addition to SNPs, structural variations, including insertions, deletions, inversions and copy number variants, with important implications on tumor biology $(79,80)$. Evaluating the link among genetic variants, epigenetic modifications and disease predispositions is currently an active area of investigation $(79,80)$.

Of note, there are several ways in which the processes of miRNA production, stability and maturation can be orchestrated (89-91). A semi-miRNA of 12 nucleotides in length, which correspond to the 5 ' region of the miRNA, let-7, is generated along the miRNA pathway, and may be involved in the control of gene expression by regulating the activity of mature miRNAs in vivo (92). Novel mechanisms for miRNA biogenesis have been described, and may be important as cancer drivers (93). Winter et al provided the first evidence that a small number of miRNAs are generated from single-stranded loop regions of human pre-miRNA hairpins, termed loop-miRs (94). In addition, an alternative miRNA processing pathway has been found in Drosophila melanogaster and Caenorhabditis elegans, which bypasses DROSHA and uses a splicing technique to generate miRNA precursors from short intronic sequences $(95,96)$. The genetic polymorphisms and the functional implications of these novel pathways require further investigation.

\section{Conclusion}

The present review focused on the predictive role of genetic variations in miRNA regulatory networks on inherited cancer 
risk and progression. Although the biological mechanisms underlying their effects on miRNA maturation and cancer development remain to be fully elucidated, our knowledge of the myriad of pathways in malignancy has improved, and further investigations of miRNA polymorphisms hold promise in advancing knowledge in the field of pharmacogenomics, molecular epidemiology and personalized medicine.

\section{Acknowledgements}

This review was supported by the National Natural Science Foundation of China (grant nos. 81273595, 81522048 and 81573511) and the National High Technology Research and Development Program (grant nos. 2012AA02A518 and 2012AA02A517).

\section{References}

1. Lagos-Quintana M, Rauhut R, Lendeckel W and Tuschl T: Identification of novel genes coding for small expressed RNAs. Science 294: 853-858, 2001.

2. Lau NC, Lim LP, Weinstein EG and Bartel DP: An abundant class of tiny RNAs with probable regulatory roles in Caenorhabditis elegans. Science 294: 858-862, 2001.

3. Lee RC and Ambros V: An extensive class of small RNAs in Caenorhabditis elegans. Science 294: 862-864, 2001.

4. Selbach M, Schwanhäusser B, Thierfelder N, Fang Z, Khanin R and Rajewsky N: Widespread changes in protein synthesis induced by microRNAs. Nature 455: 58-63, 2008.

5. Baek D, Villén J, Shin C, Camargo FD, Gygi SP and Bartel DP: The impact of microRNAs on protein output. Nature 455: 64-71, 2008.

6. Ambros V: MicroRNA pathways in flies and worms: Growth, death, fat, stress and timing. Cell 113: 673-676, 2003.

7. Bartel DP: MicroRNAs: Genomics, biogenesis, mechanism and function. Cell 116: 281-297, 2004.

8. Lee Y, Ahn C, Han J, Choi H, Kim J, Yim J, Lee J, Provost P, Rådmark O, Kim S and Kim VN: The nuclear RNase III Drosha initiates microRNA processing. Nature 425: 415-419, 2003.

9. Cullen BR: Transcription and processing of human microRNA precursors. Mol Cell 16: 861-865, 2004.

10. Lund E, Güttinger S, Calado A, Dahlberg JE and Kutay U: Nuclear export of microRNA precursors. Science 303: 95-98, 2004.

11. Mishra PJ and Bertino JR: MicroRNA polymorphisms: The future of pharmacogenomics, molecular epidemiology and individualized medicine. Pharmacogenomics 10: 399-416, 2009.

12. Calin GA, Sevignani C, Dumitru CD, Hyslop T, Noch E, Yendamuri S, Shimizu M, Rattan S, Bullrich F, Negrini $M$ and Croce CM: Human microRNA genes are frequently located at fragile sites and genomic regions involved in cancers. Proc Natl Acad Sci USA 101: 2999-3004, 2004.

13. Medina PP, Nolde $M$ and Slack FJ: OncomiR addiction in an in vivo model of microRNA-21-induced pre-B-cell lymphoma. Nature 467: 86-90, 2010.

14. Mishra PJ, Mishra PJ, Banerjee D and Bertino JR: MiRSNPs or MiR-polymorphisms, new players in microRNA mediated regulation of the cell: Introducing microRNA pharmacogenomics. Cell Cycle 7: 853-858, 2008.

15. Ryan BM, Robles AI and Harris CC: Genetic variation in microRNA networks: The implications for cancer research. Nat Rev Cancer 10: 389-402, 2010.

16. Salzman DW and Weidhaas JB: SNPing cancer in the bud: MicroRNA and microRNA-target site polymorphisms as diagnostic and prognostic biomarkers in cancer. Pharmacol Ther 137: $55-63,2013$.

17. Noh H, Hong S, Dong Z, Pan ZK, Jing Q and Huang S: Impaired MicroRNA processing facilitates breast cancer cell invasion by upregulating Urokinase-Type plasminogen activator expression. Genes Cancer 2: 140-150, 2011.

18. Sung H, Lee KM, Choi JY, Han S, Lee JY, Li L, Park SK, Yoo KY, Noh DY, Ahn SH and Kang D: Common genetic polymorphisms of microRNA biogenesis pathway genes and risk of breast cancer: A case-control study in Korea. Breast Cancer Res Treat 130: 939-951, 2011.
19. Jiang Y, Chen J, Wu J, Hu Z, Qin Z, Liu X, Guan X, Wang Y, Han J, Jiang T, et al: Evaluation of genetic variants in microRNA biosynthesis genes and risk of breast cancer in Chinese women. Int J Cancer 133: 2216-2224, 2013.

20. Sung H, Jeon S, Lee KM, Han S, Song M, Choi JY, Park SK, Yoo KY, Noh DY, Ahn SH and Kang D: Common genetic polymorphisms of microRNA biogenesis pathway genes and breast cancer survival. Bmc Cancer 12: 195, 2012.

21. Sung H, Zhang B, Choi JY, Long J, Park SK, Yoo KY, Noh DY, Ahn SH, Zheng W and Kang D: Common genetic variants in the microRNA biogenesis pathway are not associated with breast cancer risk in Asian women. Cancer Epidemiol Biomarkers Prev 21: 1385-1387, 2012.

22. Lin J, Horikawa Y, Tamboli P, Clague J, Wood CG and Wu X: Genetic variations in microRNA-related genes are associated with survival and recurrence in patients with renal cell carcinoma. Carcinogenesis 31: 1805-1812, 2010.

23. Weng Y, Chen Y, Chen J, Liu Y and Bao T: Common genetic variants in the microRNA biogenesis pathway are associated with malignant peripheral nerve sheath tumor risk in a Chinese population. Cancer Epidemiol 37: 913-916, 2013.

24. Ke HL, Chen M, Ye Y, Hildebrandt MA, Wu WJ, Wei H, Huang M, Chang DW, Dinney CP and Wu X: Genetic variations in micro-RNA biogenesis genes and clinical outcomes in non-muscle-invasive bladder cancer. Carcinogenesis 34: 1006-1011, 2013.

25. Yi R, Doehle BP, Qin Y, Macara IG and Cullen BR: Overexpression of exportin 5 enhances RNA interference mediated by short hairpin RNAs and microRNAs. Rna 11: 220-226, 2005.

26. Zeng Y and Cullen BR: Structural requirements for pre-microRNA binding and nuclear export by Exportin 5. Nucleic Acids Res 32: 4776-4785, 2004.

27. Ding C, Li C, Wang H, Li B and Guo Z: A miR-SNP of the XPO5 gene is associated with advanced non-small-cell lung cancer. Onco Targets Ther 6: 877-881, 2013.

28. Guo Z, Wang H, Li Y, Li B, Li C and Ding C: A microRNA-related single nucleotide polymorphism of the XPO5 gene is associated with survival of small cell lung cancer patients. Biomed Rep 1: 545-548, 2013.

29. Liu S, An J, Lin J, Liu Y, Bao L, Zhang W and Zhao JJ: Single nucleotide polymorphisms of microRNA processing machinery genes and outcome of hepatocellular carcinoma. PLoS One 9: e92791, 2014.

30. Leaderer D, Hoffman AE, Zheng T, Fu A, Weidhaas J, Paranjape T and Zhu Y: Genetic and epigenetic association studies suggest a role of microRNA biogenesis gene exportin-5 (XPO5) in breast tumorigenesis. Int J Mol Epidemiol Genet 2: 9-18, 2011.

31. Ma H, Yuan H, Yuan Z, Yu C, Wang R, Jiang Y, Hu Z, Shen H and Chen N: Genetic variations in key microRNA processing genes and risk of head and neck cancer: A case-control study in Chinese population. PLoS One 7: e47544, 2012.

32. Chen J, Qin Z, Pan S, Jiang J, Liu L, Liu J, Chen X, Hu Z and Shen $\mathrm{H}$ : Genetic variants in RAN, DICER and HIWI of microRNA biogenesis genes and risk of cervical carcinoma in a Chinese population. Chin J Cancer Res 25: 565-571, 2013.

33. Liu L, An J, Liu J, Wen J, Zhai X, Liu Y, Pan S, Jiang J, Wen Y, Liu Z, et al: Potentially functional genetic variants in microRNA processing genes and risk of HBV-related hepatocellular carcinoma. Mol Carcinog 52 (Suppl 1): E148-E154, 2013.

34. Liu J, Liu J, Wei M, He Y, Liao B, Liao G, Li H and Huang J: Genetic variants in the microRNA machinery gene GEMIN4 are associated with risk of prostate cancer: A case-control study of the Chinese Han population. Dna Cell Biol 31: 1296-1302, 2012.

35. Liang D, Meyer L, Chang DW, Lin J, Pu X, Ye Y, Gu J, Wu X and Lu K: Genetic variants in MicroRNA biosynthesis pathways and binding sites modify ovarian cancer risk, survival and treatment response. Cancer Res 70: 9765-9776, 2010.

36. Horikawa Y, Wood CG, Yang H, Zhao H, Ye Y, Gu J, Lin J, Habuchi T and Wu X: Single nucleotide polymorphisms of microRNA machinery genes modify the risk of renal cell carcinoma. Clin Cancer Res 14: 7956-7962, 2008.

37. Wan D, He M, Wang J, Qiu X,Zhou W, Luo Z, Chen J and Gu J: Two variants of the human hepatocellular carcinoma-associated HCAP1 gene and their effect on the growth of the human liver cancer cell line Hep3B. Genes Chromosomes Cancer 39: 48-58, 2004.

38. Adams BD, Claffey KP and White BA: Argonaute-2 expression is regulated by epidermal growth factor receptor and mitogen-activated protein kinase signaling and correlates with a transformed phenotype in breast cancer cells. Endocrinology 150: 14-23, 2009. 
39. Kim MS, Oh JE, Kim YR, Park SW, Kang MR, Kim SS, Ahn CH, Yoo NJ and Lee SH: Somatic mutations and losses of expression of microRNA regulation-related genes AGO2 and TNRC6A in gastric and colorectal cancers. J Pathol 221: 139-146, 2010.

40. Zhou Y, Chen L, Barlogie B, Stephens O, Wu X, Williams DR, Cartron MA, van Rhee F, Nair B, Waheed S, et al: High-risk myeloma is associated with global elevation of miRNAs and overexpression of EIF2C2/AGO2. Proc Natl Acad Sci USA 107: 7904-7909, 2010

41. Yang Q, Jie Z, Ye S, Li Z, Han Z, Wu J, Yang C and Jiang Y: Genetic variations in miR-27a gene decrease mature miR-27a level and reduce gastric cancer susceptibility. Oncogene 33: 193-202, 2014.

42. Zhang N, Huo Q, Wang X, Chen X, Long L, Jiang L, Ma T and Yang Q: A genetic variant in pre-miR-27a is associated with a reduced breast cancer risk in younger Chinese population. Gene 529: 125-130, 2013.

43. Yang R, Schlehe B, Hemminki K, Sutter C, Bugert P, Wappenschmidt B, Volkmann J, Varon R, Weber BH, Niederacher D, et al: A genetic variant in the pre-miR-27a oncogene is associated with a reduced familial breast cancer risk. Breast Cancer Res Treat 121: 693-702, 2010.

44. Shi D, Li P, Ma L, Zhong D, Chu H, Yan F, Lv Q, Qin C, Wang W, Wang $\mathrm{M}$, et al: A genetic variant in pre-miR-27a is associated with a reduced renal cell cancer risk in a Chinese population. PLoS One 7: e46566, 2012

45. Xu J, Yin Z, Shen H, Gao W, Qian Y, Pei D, Liu L and Shu Y: A genetic polymorphism in pre-miR-27a confers clinical outcome of non-small cell lung cancer in a Chinese population. PLoS One 8: e79135, 2013

46. Hezova R, Kovarikova A, Bienertova-Vasku J, Sachlova M, Redova M, Vasku A, Svoboda M, Radova L, Kiss I, Vyzula R and Slaby O: Evaluation of SNPs in miR-196-a2, miR-27a and miR-146a as risk factors of colorectal cancer. World J Gastroenterol 18 : 2827-2831, 2012

47. Xu Q, He CY, Liu JW and Yuan Y: Pre-miR-27a rs895819A/G polymorphisms in cancer: A meta-analysis. PLoS One 8: e65208, 2013

48. Wang Z, Lai J, Wang Y, Nie W and Guan X: The Hsa-miR-27a rs895819 (A>G) polymorphism and cancer susceptibility. Gene 521: $87-90,2013$

49. Zhong S, Chen Z, Xu J, Li W and Zhao J: Pre-mir-27a rs895819 polymorphism and cancer risk: A meta-analysis. Mol Biol Rep 40: 3181-3186, 2013.

50. Xu W, Xu J, Liu S, Chen B, Wang X, Li Y, Qian Y, Zhao W and Wu J: Effects of common polymorphisms rs11614913 in miR-196a2 and rs2910164 in miR-146a on cancer susceptibility: A meta-analysis PLoS One 6: e20471, 2011.

51. Wang J, Wang Q, Liu H, Shao N, Tan B, Zhang G, Wang K, Jia Y, Ma W, Wang N and Cheng Y: The association of miR-146a rs2910164 and miR-196a2 rs11614913 polymorphisms with cancer risk: A meta-analysis of 32 studies. Mutagenesis 27: 779-788, 2012

52. Srivastava K and Srivastava A: Comprehensive review of genetic association studies and meta-analyses on miRNA polymorphisms and cancer risk. PLoS One 7: e50966, 2012.

53. Wang PY, Gao ZH, Jiang ZH, Li XX, Jiang BF and Xie SY: The associations of single nucleotide polymorphisms in miR-146a, miR-196a and miR-499 with breast cancer susceptibility. PLoS One 8: e70656, 2013

54. Chen Z, Xu L, Ye X, Shen S, Li Z, Niu X and Lu S: Polymorphisms of microRNA sequences or binding sites and lung cancer: A meta-analysis and systematic review. PLoS One 8: e61008, 2013.

55. Yuan Z, Zeng X, Yang D, Wang W and Liu Z: Effects of common polymorphism rs11614913 in Hsa-miR-196a2 on lung cancer risk. PLoS One 8: e61047, 2013

56. Xu Y, Li L, Xiang X, Wang H, Cai W, Xie J, Han Y, Bao S and Xie Q: Three common functional polymorphisms in microRNA encoding genes in the susceptibility to hepatocellular carcinoma: A systematic review and meta-analysis. Gene 527: 584-593, 2013.

57. Wan D, Gu W, Xu G, Shen C, Ding D, Shen S, Wang S, Gong X, $\mathrm{He}$ S and Zhi Q: Effects of common polymorphisms rs2910164 in miR-146a and rs11614913 in miR-196a2 on susceptibility to colorectal cancer: A systematic review meta-analysis. Clin Transl Oncol 16: 792-800, 2014.

58. Guo J, Jin M, Zhang M and Chen K: A genetic variant in miR-196a2 increase digestive system cancer risks: A meta-analysis of 15 case-control studies. PLoS One 7: e30585, 2012.

59. Yoon KA, Yoon H, Park S, Jang HJ, Zo JI, Lee HS and Lee JS: The prognostic impact of microRNA sequence polymorphisms on the recurrence of patients with completely resected non-small cell lung cancer. J Thorac Cardiovasc Surg 144: 794-807, 2012.
60. Hu Z, Chen J, Tian T, Zhou X, Gu H, Xu L, Zeng Y, Miao R, Jin G, $\mathrm{Ma} \mathrm{H}$, et al: Genetic variants of miRNA sequences and non-small cell lung cancer survival. J Clin Invest 118: 2600-2608, 2008.

61. Li L, Chen XP and Li YJ: MicroRNA-146a and human disease. Scand J Immunol 71: 227-231, 2010.

62. Bhaumik D, Scott GK, Schokrpur S, Patil CK, Campisi J and Benz CC: Expression of microRNA-146 suppresses NF-kappaB activity with reduction of metastatic potential in breast cancer cells. Oncogene 27: 5643-5647, 2008.

63. Lin SL, Chiang A, Chang D and Ying SY: Loss of mir-146a function in hormone-refractory prostate cancer. RNA 14: 417-424, 2008.

64. Jazdzewski K, Murray EL, Franssila K, Jarzab B, Schoenberg DR and de la Chapelle A: Common SNP in pre-miR-146a decreases mature miR expression and predisposes to papillary thyroid carcinoma. Proc Natl Acad Sci USA 105: 7269-7274, 2008.

65. Jiang H, He X, Li J, Xie Q, Lin J and Chang Y: Association of a single-nucleotide polymorphism within the miR-146a gene with susceptibility for acute-on-chronic hepatitis B liver failure. Immunogenetics 65: 257-263, 2013.

66. Zhou X, Chen X, Hu L, Han S, Qiang F, Wu Y, Pan L, Shen H, $\mathrm{Li} \mathrm{Y}$ and $\mathrm{Hu} \mathrm{Z}$ : Polymorphisms involved in the miR-218-LAMB3 pathway and susceptibility of cervical cancer, a case-control study in Chinese women. Gynecol Oncol 117: 287-290, 2010.

67. Kertesz M, Iovino N, Unnerstall U, Gaul U and Segal E: The role of site accessibility in microRNA target recognition. Nat Genet 39: $1278-1284,2007$

68. Liu Z, Li G, Wei S, Niu J, El-Naggar AK, Sturgis EM and Wei Q: Genetic variants in selected pre-microRNA genes and the risk of squamous cell carcinoma of the head and neck. Cancer 116: 4753-4760, 2010.

69. Chen QH, Wang QB and Zhang B: Ethnicity modifies the association between functional microRNA polymorphisms and breast cancer risk: A HuGE meta-analysis. Tumour Biol 35: 529-543, 2014

70. Li Y, Liu J, Yuan C, Cui B, Zou X and Qiao Y: High-risk human papillomavirus reduces the expression of microRNA-218 in women with cervical intraepithelial neoplasia. J Int Med Res 38: 1730-1736, 2010 .

71. Shi TY, Chen XJ, Zhu ML, Wang MY, He J, Yu KD, Shao ZM, Sun $\mathrm{MH}$, Zhou XY, Cheng X, et al: A pri-miR-218 variant and risk of cervical carcinoma in Chinese women. Bmc Cancer 13: 19, 2013.

72. Zhang LS, Liang WB, Gao LB, Li HY, Li LJ, Chen PY, Liu Y, Chen TY, Han JG, Wei YG, et al: Association between pri-miR-218 polymorphism and risk of hepatocellular carcinoma in a Han Chinese population. Dna Cell Biol 31: 761-765, 2012.

73. Cipollini M, Landi S and Gemignani F: MicroRNA binding site polymorphisms as biomarkers in cancer management and research Pharmgenomics Pers Med 7: 173-191, 2014.

74. Georges M, Clop A, Marcq F, Takeda H, Pirottin D, Hiard S, Tordoir X, Caiment F, Meish F, Bibé B, et al: Polymorphic microRNA-target interactions: A novel source of phenotypic variation. Cold Spring Harb Symp Quant Biol 71: 343-350, 2006.

75. Pu X, Roth JA, Hildebrandt MA, Ye Y, Wei H, Minna JD, Lippman SM and Wu X: MicroRNA-related genetic variants associated with clinical outcomes in early-stage non-small cell lung cancer patients. Cancer Res 73: 1867-1875, 2013.

76. McEvoy J, Ulyanov A, Brennan R, Wu G, Pounds S, Zhang J and Dyer MA: Analysis of MDM2 and MDM4 single nucleotide polymorphisms, mRNA splicing and protein expression in retinoblastoma. PLoS One 7: e42739, 2012.

77. Zhou L, Zhang X, Li Z, Zhou C, Li M, Tang X, Lu C, Li H, Yuan Q and Yang M: Association of a genetic variation in a miR-191 binding site in MDM4 with risk of esophageal squamous cell carcinoma. PLoS One 8: e64331, 2013.

78. Wynendaele J, Böhnke A, Leucci E, Nielsen SJ, Lambertz I, Hammer S, Sbrzesny N, Kubitza D, Wolf A, Gradhand E, et al: An illegitimate microRNA target site within the 3' UTR of MDM4 affects ovarian cancer progression and chemosensitivity. Cancer Res 70: 9641-9649, 2010.

79. Wang C, Zhao H, Zhao X, Wan J, Wang D, Bi W, Jiang X and Gao Y: Association between an insertion/deletion polymorphism within 3'UTR of SGSM3 and risk of hepatocellular carcinoma. Tumour Biol 35: 295-301, 2014.

80. Zhu Z, Jiang Y, Chen S, Jia S, Gao X, Dong D and Gao Y: An insertion/deletion polymorphism in the $3^{\prime}$ untranslated region of type I collagen a2 (COL1A2) is associated with susceptibility for hepatocellular carcinoma in a Chinese population. Cancer Genet 204: 265-269, 2011 
81. Jin Y, Xu G, Huang J, Zhou D, Huang X and Shen L: Analysis of the association between an insertion/deletion polymorphism within the 3' untranslated region of COL1A2 and chronic venous insufficiency. Ann Vasc Surg 27: 959-963, 2013.

82. Ioannidis JP, Ntzani EE, Trikalinos TA and Contopoulos-Ioanni dis DG: Replication validity of genetic association studies. Nat Genet 29: 306-309, 2001.

83. Chanock SJ, Manolio T, Boehnke M, Boerwinkle E, Hunter DJ, Thomas G, Hirschhorn JN, Abecasis G, Altshuler D; NCI-NHGRI Working Group on Replication in Association Studies, et al: Replicating genotype-phenotype associations. Nature 447: 655-660, 2007.

84. Fabbri M, Ivan M, Cimmino A, Negrini $M$ and Calin GA: Regulatory mechanisms of microRNAs involvement in cancer. Expert Opin Biol Ther 7: 1009-1019, 2007.

85. Silber J, Lim DA, Petritsch C, Persson AI, Maunakea AK, Yu M, Vandenberg SR, Ginzinger DG, James CD, Costello JF, et al: MiR-124 and miR-137 inhibit proliferation of glioblastoma multiforme cells and induce differentiation of brain tumor stem cells. BMC Med 6: 14, 2008

86. Agirre X, Vilas-Zornoza A,Jiménez-Velasco A, Martin-Subero JI, Cordeu L, Gárate L, San José-Eneriz E, Abizanda G, Rodríguez-Otero P, Fortes P, et al: Epigenetic silencing of the tumor suppressor microRNA Hsa-miR-124a regulates CDK6 expression and confers a poor prognosis in acute lymphoblastic leukemia. Cancer Res 69: 4443-4453, 2009.

87. Pang RT, Leung CO, Ye TM, Liu W, Chiu PC, Lam KK, Lee KF and Yeung WS: MicroRNA-34a suppresses invasion through downregulation of Notch1 and Jagged1 in cervical carcinoma and choriocarcinoma cells. Carcinogenesis 31: 1037-1044, 2010.
88. Majid S, Dar AA, Saini S, Arora S, Shahryari V, Zaman MS, Chang I, Yamamura S, Tanaka Y, Deng G and Dahiya R: MiR-23b represses proto-oncogene Src kinase and functions as methylation-silenced tumor suppressor with diagnostic and prognostic significance in prostate cancer. Cancer Res 72: 6435-6446, 2012.

89. Zisoulis DG, Kai ZS, Chang RK and Pasquinelli AE: Autoregulation of microRNA biogenesis by let-7 and Argonaute. Nature 486: 541-544, 2012.

90. Juvvuna PK, Khandelia P, Lee LM and Makeyev EV: Argonaute identity defines the length of mature mammalian microRNAs. Nucleic Acids Res 40: 6808-6820, 2012.

91. Yang JS, Maurin T and Lai EC: Functional parameters of Dicer-independent microRNA biogenesis. RNA 18: 945-957, 2012.

92. Plante I, Plé H, Landry P, Gunaratne PH and Provost P: Modulation of microRNA activity by Semi-microRNAs. Front Genet 3: 99, 2012

93. Faller M and Guo F: MicroRNA biogenesis: There's more than one way to skin a cat. Biochim Biophys Acta 1779: 663-667, 2008.

94. Winter J, Link S, Witzigmann D, Hildenbrand C, Previti C and Diederichs S: Loop-miRs: Active microRNAs generated from single-stranded loop regions. Nucleic Acids Res 41: 5503-5512, 2013.

95. Berezikov E, Liu N, Flynt AS, Hodges E, Rooks M, Hannon GJ and Lai EC: Evolutionary flux of canonical microRNAs and mirtrons in Drosophila. Nat Genet 42: 6-9, 2010.

96. Ruby JG, Jan CH and Bartel DP: Intronic microRNA precursors that bypass Drosha processing. Nature 448: 83-86, 2007. 